\title{
Developing a Public Health Maternal and Child Health Training Program: Lessons Learned from Five Schools of Public Health
}

\author{
Christine T. Bozlak ${ }^{1}$ (D) Q Qiana L. Brown ${ }^{2} \cdot$ Renee Davis $^{3} \cdot$ Rachel de Long $^{1} \cdot$ Melissa M. Howard ${ }^{4} \cdot$ Teri E. Lassiter $^{5}$. \\ Maria J. Perez-Patron ${ }^{6} \cdot$ Brandie DePaoli Taylor $^{7} \cdot$ Renee Turchi $^{8} \cdot$ Michelle Menser Tissue $^{9}$
}

Accepted: 24 November 2021 / Published online: 3 January 2022

(c) The Author(s) 2021

\begin{abstract}
Maternal and child health (MCH), as a core sub-field of public health, continues to be an essential area in which additional workforce development and investment are needed. Recent public health workforce assessments in the United States reveal there will be a significant number of vacancies in $\mathrm{MCH}$ public health positions in the near future, creating the need for a well-trained and skilled public health $\mathrm{MCH}$ workforce. In order to address this potential critical workforce gap, the U.S. Department of Health and Human Services, Health Resources and Services Administration's Maternal and Child Health Bureau initiated the Maternal and Child Health Public Health Catalyst Program in 2015 to support the creation of MCH training programs in accredited schools of public health that previously did not have a MCH concentration. This article details the accomplishments and lessons learned from the first five MCH Catalyst Program grantees: Drexel University; Florida International University; Rutgers, The State University of New Jersey; Texas A\&M University; and the University at Albany.
\end{abstract}

Keywords MCH workforce development $\cdot$ Graduate education $\cdot$ Schools of public health $\cdot \mathrm{MCH}$ training program

Christine T. Bozlak

cbozlak@albany.edu

Qiana L. Brown

qiana.brown@ rutgers.edu

Renee Davis

Rk38@drexel.edu

Rachel de Long

rdelong@albany.edu

Melissa M. Howard

mehoward@fiu.edu

Teri E. Lassiter

lassiter@sph.rutgers.edu

Maria J. Perez-Patron

maria.perez@tamu.edu

Brandie DePaoli Taylor

bradtayl@utmb.edu

Renee Turchi

Renee.turchi@towerhealth.org

Michelle Menser Tissue

MTissue@hrsa.gov

1 Health Policy, Management, and Behavior, University at Albany School of Public Health, One University Place, Rm 173, Rensselaer, NY 12144, USA

2 School of Social Work, Rutgers, The State University of New Jersey, 390 George Street, Suite 508, New Brunswick, NJ 08901, USA
3 Department of Community Health \& Prevention, Dornsife School of Public Health, Drexel University, 3215 Market St, 4th Floor, Philadelphia, PA 19104, USA

4 Department of Health Promotion and Disease Prevention, Robert Stempel College of Public Health \& Social Work, Florida International University, 11200 SW 8th Street, Miami, FL 33199, USA

5 Diversity, Equity, \& Inclusion, Urban-Global Public Health, Rutgers School of Public Health, 1 Riverfront Plaza, Suite 1020, 10th Floor, Newark, NJ 07076, USA

6 Department of Epidemiology and Biostatistics, Texas A\&M School of Public Health, 212 Adriance Lab Rd, College Station, TX 77843-1288, USA

7 Obstetrics and Gynecology, Preventative Medicine \& Community Health, Division of Basic \& Translational Research, The University of Texas Medical Branch, MRB 11.158A, 301 University Blvd., Galveston, TX 77555, USA

8 Pediatrics \& Pediatrician-in-Chief, St. Christopher's Hospital for Children, Center for Children and Youth With Special Healthcare Needs, Maternal and Child Health Program, Drexel University College of Medicine and Drexel Dornsife School of Public Health, 3215 Market Street, Philadelphia, PA 19104, USA

9 Maternal and Child Health Bureau, 5600 Fishers Ln., Rockville, MD 20857, USA 


\section{Significance}

This manuscript is the first to detail the accomplishments and lessons learned from the first five years of the HRSA Maternal and Child Health Bureau's MCH Public Health Catalyst Program.

\section{Introduction}

Maternal and child health (MCH), a sub-field of public health, continues to be an essential area in which workforce development and investment are needed. According to an Association of Maternal and Child Health Programs (AMCHP) analysis of the 2017 Public Health Workforce Interests and Needs Survey (PH WINS; de Beaumont Foundation, 2017), 24\% of the MCH workforce surveyed plan to retire within the next five years, and the workforce, at all levels, indicated a need for additional $\mathrm{MCH}$ knowledge and skill development (AMCHP, n.d.). Consequently, an urgent need to fill these vacancies with a well-trained public health $\mathrm{MCH}$ workforce is anticipated. However, only $14 \%$ of the current state and local governmental $\mathrm{MCH}$ workforce has received formal public health training (AMCHP, n.d.). To appropriately address population-level $\mathrm{MCH}$ needs, a structure is needed to ensure the $\mathrm{MCH}$ workforce is adequately trained in public health and the MCH Leadership Competencies (U.S., 2018). MCH public health training programs provide one solution. This article will discuss initial outcomes and lessons learned from the first five Health Resources and Services Administration (HRSA)-funded MCH Public Health Catalyst Training Programs (referred to as "Catalyst Programs" and "Programs") in the United States, which included the following institutions: Drexel University; Florida International University; Rutgers, The State University of New Jersey; Texas A\&M University; and the University at Albany.

The Health Resources and Services Administration's Maternal and Child Health Bureau (MCHB) has supported MCH Training Programs since the 1940s (Hutchins, 1994) and currently administers a continuum of workforce development programs, including academic training programs, to ensure the future and practicing $\mathrm{MCH}$ workforce is trained in the unique needs of MCH populations (US DHHS HRSA MCHB, n.d.a.). MCHB's public health workforce development efforts are supported through funding from the Special Projects of Regional and National Significance, administered as part of Title V of the Social Security $\mathrm{Act}^{1}$ (US DHHS

\footnotetext{
1 The Title V MCH Block Grant Program is a formula grant under which funds are awarded to 59 states and jurisdictions to support the health and well-being of all mothers, infants, and children, which includes infants and children with special health care needs (CSHCN), and their families. (US DHHS HRSA MCHB, n.d.b.).
}

HRSA, n.d.). These efforts emphasize preparing future $\mathrm{MCH}$ professionals who are equipped to work in Title $\mathrm{V}$ agencies and to support academic-practice partnerships between $\mathrm{MCH}$ academic programs and state $\mathrm{MCH}$ agencies.

These programs have played a critical role in developing the MCH workforce infrastructure across the country, and $\mathrm{MCH}$ training programs' impact, excluding the Catalyst Programs, has previously been documented (Kavanagh et al., 2015). While MCHB has supported MCH training in Schools of Public Health (SPH) over time, including the Centers of Excellence in MCH Education, Science and Practice Program (CoEs), recent workforce assessments highlight the need to expand $\mathrm{MCH}$ public health curriculum in Schools of Public Health and to train a diverse $\mathrm{MCH}$ public health workforce representative of the U.S. population (Association of Maternal and Child Health Programs. (n.d.a.); de Beaumont Foundation., 2017). In response to these identified workforce development needs, MCHB established the MCH Public Health Catalyst Program in 2015.

The five initial Catalyst Programs were awarded based on a competitive, objective review of applications in response to an MCHB-issued Notice of Funding Opportunity. With this program, the number of SPH with $\mathrm{MCH}$ public health content has increased, and there is expanded geographic diversity in $\mathrm{MCH}$ degree offerings. The Catalyst Programs also bring a strong emphasis on recruiting $\mathrm{MCH}$ students from racial and ethnic groups that are underrepresented in the MCH workforce. MCHB awarded each Catalyst Program up to $\$ 70,000$ per year for five years. Each program was encouraged to pursue additional funding sources to build sustainability.

The MCH Public Health Catalyst Program goals are to: (1) develop foundational $\mathrm{MCH}$ content and competencies within SPH where no $\mathrm{MCH}$ concentration currently exists; (2) provide $\mathrm{MCH}$ content exposure to an increased number of public health students, introducing students to careers in the MCH field; and (3) recruit graduate students who are from backgrounds (including racial and ethnic minorities) underrepresented in the $\mathrm{MCH}$ field. The purpose of this article is to describe the facilitators and challenges of implementing an academic MCH program in accredited U.S. Schools of Public Health where a program did not already exist. This article will report on early successes, initial programmatic impacts, and lessons learned to inform other academic institutions that also aspire to integrate $\mathrm{MCH}$ into their curricula.

\section{Methods}

Data reported to MCHB from the five initial Catalyst Programs funded from 2015 to 2020, and additional data provided from each program's evaluation system, were 
analyzed. MCHB collects performance measure data from grantees annually through the Discretionary Grants Information System (DGIS) to assess progress in attaining program goals. This reporting mechanism has been the impetus for Catalyst Programs to create internal evaluation processes to demonstrate their impact and areas in need of enhancement.

Multiple measures of interest were analyzed based on Catalyst Program performance measure submissions to HRSA from Fiscal Years 2015-2019 and outcome data collected and reported by trainees in the post-training period. Outcomes of interest at two-years post-training include the percentage of Catalyst Program graduates demonstrating $\mathrm{MCH}$ field leadership after graduation, and the percentage of graduates engaged in work related to $\mathrm{MCH}$ populations. Field leadership is defined as providing $\mathrm{MCH}$ leadership within the clinical, advocacy, academic, research, public health, public health policy, or governmental realms in a variety of activities, but not necessarily managerial roles. An example of a public health practice leadership activity is procuring a grant or other funding in an $\mathrm{MCH}$ area.

Additional data collected through DGIS and aggregated across programs include the number of trainees at each institution and the diversity of trainees. Catalyst Program directors also supplied aggregated programmatic quantitative and qualitative data related to their trainees, infrastructure, administration, as well as reflections as program directors on challenges and barriers. This article is not based upon clinical study or patient data, and it was determined that Institutional Review Board approval was not needed for the collection of these programmatic data or for this article.

\section{Results/Initial Program Outcomes}

The results and initial program outcomes from the first five years of funding for the initial Catalyst Programs are described below. Due to evaluation and data collection methods, trainee diversity and alumni data are only reported for 2015-2019.

\section{Program Structure and Curricula/Academic Programs}

One specific goal of the Catalyst Program initiative was to ensure that foundational $\mathrm{MCH}$ content was delivered for at least nine months of every grant year (U.S., 2014). Within the first year (2015-2016), all Catalyst Programs developed foundational $\mathrm{MCH}$ courses covering the historical, legislative, and public health systems knowledge base regarding Title V and related programs in the United States. In one program, the foundational $\mathrm{MCH}$ course partnered with the state's Title $\mathrm{V}$ program on a project related to current state and national $\mathrm{MCH}$ priorities.
$\mathrm{MCH}$ courses covered the empirical and theoretical basis for a life course perspective in addressing the unique developmental needs of $\mathrm{MCH}$ populations. A health equity and epidemiologic framework was used to understand these needs in the context of physical, social, and environmental influences and interactions. All programs addressed cultural and linguistic competency by stressing the importance of developing these skills for public health practice. The programs are grounded in the MCH Leadership Competencies (U.S., 2018), and informed by regional and national MCH needs assessments. Created in 2007, these competencies are a set of knowledge, skills, and personal characteristics that are designed to guide the professional development of all U.S. MCH professionals (U.S., 2018). Catalyst Programs used the competencies to develop curricula and professional development opportunities. Some programs continue to use them to assess individual trainee development. Although it was not a requirement of the training grant, all the programs developed $\mathrm{MCH}$ academic graduate certificates, concentrations, and/or a minor within the five-year grant period with a range of participation. At the end of the grant period, two programs had just begun to recruit students for their new academic programs and one program had enrolled 40 students.

The structure of the Catalyst Programs varied by institution. All programs included faculty who served as program director/co-directors. Affiliated faculty with $\mathrm{MCH}$ teaching and research interests were identified to expand the institution's MCH network and strengthen trainee mentorship, research, and curriculum development. In total, the number of affiliated faculty ranged from 3 to 19 across each of the programs. Programs used a variety of methods to communicate with and use faculty expertise within their own institutions to support the development of their trainees, build a $\mathrm{MCH}$ learning community, and achieve their $\mathrm{MCH}$ program goals, including meetings, faculty work groups, and email listserv communications.

\section{Trainee Engagement}

Given the uniqueness of each institution, trainee engagement looked different across programs and was tailored to meet trainee needs. From 2015 to 2020, Catalyst Programs supported $\mathrm{MCH}$ trainees in a variety of ways, including funding for: 1) travel to attend $\mathrm{MCH}$-related conferences; 2) teaching assistantships for MCH courses; 3) "Scholar Consultant" opportunities to consult on the $\mathrm{MCH}$ program and its courses by providing regular feedback while also participating in community-based participatory research projects; and 4) Stipends to provide tuition-only support for the students' MCH coursework or completion of an $\mathrm{MCH}$-focused internship. Each program developed a MCH-focused student interest group or advisory committee. The groups' structure 
Table 1 Aggregate Catalyst program race and ethnicity trainee data (2015-2019)

\begin{tabular}{llll}
\hline Year & $\begin{array}{l}\text { Total trainees that were engaged in MCH activities including } \\
\text { coursework, practicum experiences, and student interest group } \\
\text { activities during a 12-month reporting period (beyond 39 } \\
\text { contact hours) }\end{array}$ & $\begin{array}{l}\text { Percent of trainees identifying as being Percent of trainees } \\
\text { from an underrepresented racial group } \\
\text { identifying as Hispanic or } \\
\text { Latino }\end{array}$ \\
\hline 2015 & 72 & $39(54.2 \%)$ & $12(16.7 \%)$ \\
2016 & 94 & $51(54.3 \%)$ & $15(16.0 \%)$ \\
2017 & 93 & $58(62.3 \%)$ & $12(12.9 \%)$ \\
2018 & 124 & $66(53.2 \%)$ & $11(8.9 \%)$ \\
2019 & 102 & $60(58.9 \%)$ & $17(16.7 \%)$ \\
$2015-2019$ & 485 & $275(56.5 \%)$ & $67(13.8 \%)$ \\
\hline
\end{tabular}

varied with some programs meeting two to three times per year while others met bi-monthly.

Across the five institutions and five-year timeframe, 138 trainees were awarded individual funding to support their $\mathrm{MCH}$ professional development. At least 615 funded and unfunded trainees across all five programs had at least one contact hour (the minimum contact needed to be considered a MCH trainee) with the Catalyst Programs through programmatic activities from 2015 to 2020. These trainees engaged in activities, such as MCH-related seminars, journal clubs, interest groups, open houses, symposia, $\mathrm{MCH}$ courses, $\mathrm{MCH}$ academic programs, internships, listservs, an $\mathrm{MCH}$ app, mentoring, and funding opportunities for $\mathrm{MCH}$ professional development. Trainees and faculty also jointly produced publications, conference presentations, and policy briefs.

Catalyst trainees from all programs extensively engaged with their communities and public health systems serving $\mathrm{MCH}$ populations. Programs engaged trainees in over 120 collaborative activities with state Title $\mathrm{V}$ agencies and other community $\mathrm{MCH}$ partners, such as continuing education open to professionals and trainees, advocacy, peer education, and research. Programs hosted outreach and awareness events on infant mortality, sexual health, alcohol and opioid use in pregnancy, and other MCH topics. Trainees volunteered at $\mathrm{MCH}$ organizations and hosted clothing and toiletry drives for $\mathrm{MCH}$ causes, co-hosted training events with community partners, conducted $\mathrm{MCH}$ research with faculty on issues including maternal and infant health, asthma, stillbirth prevention, and food insecurity. Trainees mentored other MCH-focused students, including peers at the same educational level or below, through informal discussions, guest lectures in undergraduate $\mathrm{MCH}$ courses, and the creation of training opportunities for their peers.

At the state level, three Catalyst programs engaged with their state Title $\mathrm{V}$ programs. As new training programs, Catalyst Programs were expected by HRSA to make initial outreach to their state's Title V program to begin to build a relationship, but not to provide technical assistance. Collaborations included development of a maternal mortality prevention webcast, student recruitment for Title V placements, partnership on MCH course projects, Title V staff presentations, and technical assistance for the state's Title V needs assessment. At the national level, sixteen Catalyst trainees, representing all five Catalyst programs, participated in the Title V MCH Internship Program from 2017 to 2020, providing increased exposure to Title $\mathrm{V}$ careers for Catalyst trainees (Handler et al., 2018). All Catalyst Programs included Title $\mathrm{V}$ educational content in their curricula.

\section{Trainee Recruitment and Diversity}

One of the Catalyst Program's objectives is to recruit graduate students from backgrounds underrepresented in the MCH field. Ensuring a well-prepared, diverse and culturally competent workforce is a key strategy to reduce health disparities and to improve health outcomes (Agency for Healthcare Research \& Quality, 2018). Programs used various trainee recruitment methods for engagement with their programs, especially among diverse trainees. Some of these methods included: leveraging existing recruitment activities within their institutions to advertise trainee opportunities, developing a scholarship program which provided funds for $\mathrm{MCH}$-related research and practicum opportunities, holding recruitment open houses, and recruitment through student listservs and newsletters.

Catalyst Programs were situated within existing diverse higher education institutions that also have scholarships to recruit diverse students. Diversity recruitment efforts were closely linked with those same efforts of the program's SPH, which often included attending public health events, such as the American Public Health Association's annual meeting, for recruitment purposes. Existing undergraduate public health programs and graduate online public health programs also helped to increase the programs' diversity. Although this is an area in need of greater attention at most institutions, engaging diverse faculty within each program from various disciplines and identities through guest lectures in $\mathrm{MCH}$ courses, mentoring relationships for $\mathrm{MCH}$ trainees, and $\mathrm{MCH}$ research opportunities with trainees, also helped to recruit diverse trainees. 
Table 2 Post-graduation MCHrelated placement of trainees by Catalyst program
Drexel University

Florida International University

Rutgers University

Texas A\&M University

University at Albany
Academic organization

Clinical organization/health care setting

Other federal agency

Local health department

$\mathrm{MCH}$ advocacy organization

Community-based organization

Academic organization

Clinical organization/health care setting

Other state agency

Local health department

Community-based organization

Research institution

Other: Nursing; PhD in Public Health programs

State Title V program

Local health department

$\mathrm{MCH}$ advocacy organization

Community-based organization

Academic organization

Clinical organization/health care setting

HRSA

Other federal agency

State Title V program

Local health department

$\mathrm{MCH}$ advocacy organization

Community-based organization

Research institution

Other: International organization

Academic organization

Clinical organization/health care setting

HRSA

State Title V program

Other state agency

Local or city health department

$\mathrm{MCH}$ advocacy organization

Community-based organization

Research institution

Other: Consulting firm; K-12 schools; Professional association
As demonstrated in Table 1., for the reporting periods between 2015 and 2019, 56.5\% of Catalyst trainees were from an underrepresented racial or ethnic group, which is twice as many as the $27 \%$ of the U.S. population who self-identified as non-white during this timeframe (U.S. Census Bureau, 2019). In comparison, a 2016 Title V Workforce Assessment indicated that $76 \%$ of the Title V workforce identified as white (Association of Maternal \& Child Health Programs, 2016). Hispanic/Latinos are the largest ethnic minority in the U.S., and comprised $18 \%$ of the population (U.S. Census Bureau, 2019) and 17\% of Catalyst trainees in FY19. Goodman et al. (2020) reported that in $2016,11.9 \%$ of public health masters students and
9.9\% of doctoral students identified as Hispanic, respectively. These data are an indication that the Catalyst Programs show promise in helping to build a more diverse public health and $\mathrm{MCH}$ workforce that is representative of the U.S. population.

\section{Initial Trainee Post-Graduation MCH Career Outcomes}

In FY 19, 89\% of former trainees from the five Catalyst Programs demonstrated leadership in $\mathrm{MCH}$ two years after program completion in any of the following areas: academic, clinical, public health practice, and public policy 
Table $3 *$ Recommendations for other schools and programs of public health for MCH program initiation

\begin{tabular}{ll}
\hline During program development & During program implementation \\
\hline $\begin{array}{l}\text { Talk with other SPH with a MCH Program } \\
\text { Assess institution for MCH-focused faculty, staff, courses, and related pro- } \\
\text { grams }\end{array}$ & $\begin{array}{l}\text { Focus on publicity of program } \\
\text { Use resources, such as ATMCH, AMCHP, and MCH Navigator }\end{array}$ \\
$\begin{array}{l}\text { Gain support of administrators } \\
\text { Establish collaborations with local organizations and the state Title V program } \\
\text { Consider multiple sources of funding }\end{array}$ & $\begin{array}{l}\text { Leverage the resources/expertise of institution } \\
\text { Hire a program coordinator } \\
\text { Provide students with an opportunity for leadership, but be } \\
\text { selective }- \text { only the most motivated students are able to lead } \\
\text { others }\end{array}$ \\
Build the student pipeline through undergraduate and other academic programs & \begin{tabular}{l} 
Implement a clear evaluation plan \\
\hline
\end{tabular}
\end{tabular}

*Initially presented as a poster presentation at the 2019 Association of Maternal and Child Health Programs conference

and advocacy. Former trainees most frequently reported academic or public health practice leadership. Sixty-five percent of former trainees indicated they were working with $\mathrm{MCH}$ populations.

Through mentorship, direct linkages with external partners, networking events, job postings in e-newsletters, and providing formal recommendations, former trainees secured full-time positions in local community-based organizations (e.g. child abuse prevention organization, child care coordinating council), state Title $\mathrm{V}$ programs, and national $\mathrm{MCH}$ organizations (e.g. American College of Obstetricians and Gynecologists, March of Dimes). Former trainees are also working in federal agencies, including HRSA, the National Institutes of Health, the Centers for Disease Control and Prevention, and the Department of Veterans Affairs. Please see Table 2. for the post-graduation trainee placements of each program's trainees. Several former trainees continued with their formal education pursuing clinical degrees in nursing and medicine, doctoral degrees, and professional $\mathrm{MCH}-$ related certifications (e.g. doula and lactation certifications). Trainees also continue to serve their professional communities, such as the APHA MCH Section and the Association of Teachers of MCH (ATMCH).

\section{Discussion and Conclusion}

In 2015, the establishment of the HRSA MCH Public Health Catalyst Program resulted in the creation of five MCH Programs at Schools of Public Health throughout the United States where there was previously limited $\mathrm{MCH}$ curricula. These programs differ in their structure, operation, curricula, and professional development opportunities. However, the programs share commonalities in purpose and passion to expand the United States' MCH workforce and develop MCH leaders. These initial Catalyst Programs benefitted from having this training grant to support their creation in a coordinated manner, while also benefitting from the mentorship of the HRSA MCHB and the CoEs. HRSA MCHB and the COEs engaged in conference calls and annual grantee meetings with the Catalyst Programs to share best practices pertaining to curriculum development, trainee engagement, diversity and inclusion, and Title $\mathrm{V}$ engagement.

This article is limited by the short duration of data included (2015-2019). Despite still being in a formative state and needing to collect long-term outcome data, the initial impact of these MCH programs has been substantial. The programs have also experienced individual challenges in their development including changes in leadership and also with their state Title $\mathrm{V}$ workforce that make it difficult to establish and maintain partnerships. Programs have encountered challenges with differing levels of trainee leadership and engagement across academic years for their $\mathrm{MCH}$ student organizations.

The following are lessons learned and recommendations for other schools and programs of public health seeking to establish $\mathrm{MCH}$ programs or curricula. The field of $\mathrm{MCH}$ is multidisciplinary and interdisciplinary. $\mathrm{MCH}$ academic programs must engage other disciplines to support the diversity in $\mathrm{MCH}$ student interests. These efforts can also help with long-term program sustainability. For example, other schools outside of, but complementary to public health, may contribute resources and expertise if their students are engaged in MCH efforts. Similarly, programs should have a continued focus on establishing and maintaining strong partnerships with local MCH organizations and state Title V programs as a key element of their $\mathrm{MCH}$ programs. External partners can also help secure funding to diversify funding streams for the program.

Sustainability must be built into the program at its inception, which includes working with institutional leadership to formalize the program into the organizational structure expeditiously. The Catalyst Programs used the initial HRSA investment to begin their $\mathrm{MCH}$ programs and to leverage other funds by local foundations and state agencies. One Catalyst Program established a memorandum of understanding with the state Title $\mathrm{V}$ program to support funded trainee internships in the Title $\mathrm{V}$ program. 
New $\mathrm{MCH}$ programs are encouraged to reach out to existing $\mathrm{MCH}$ programs at other institutions for mentorship and best practices, as well as attend $\mathrm{MCH}$-focused conferences (e.g. AMCHP) for information and networking. For example, ATMCH provides free membership, curriculum resources on their website, and provided mentorship and Innovation in $\mathrm{MCH}$ Teaching awards to two of the Catalyst Programs to assist these programs with the development of their curricula. In addition to these lessons learned, Table 3. includes recommendations for institutions wanting to establish MCH Programs.

In summary, the HRSA MCH Public Health Catalyst Program grant was critical in garnering institutional and administrative support and initiating $\mathrm{MCH}$ programs at the five institutions featured in this article. In 2021, de Beaumont et. al. (2021) reported there is a need for 80,000 more full-time positions within state and local health agencies to meet community needs. The 2017 PH WINS survey indicated that more than a third of respondents from state health agencies were considering leaving their agency within the next year (Halverson, 2019). During this time when U.S. MCH populations are at increased risk for negative health outcomes and with heightened visibility of existing health disparities in these populations due to COVID-19 (Dongarwar et al., 2020; Hill \& Burroughs, 2020), it is imperative that Schools of Public Health continue to recognize the importance of $\mathrm{MCH}$ as a core field within public health and work to secure the future, growth, and diversity of the $\mathrm{MCH}$ workforce. HRSA MCHB's investment in the MCH Public Health Catalyst Program represents a promising effort to help address these persistent $\mathrm{MCH}$ workforce needs.

Acknowledgements The activities described in this article were completed by the MCH Public Health Catalyst Programs, which are programs funded by the U.S. Department of Health and Human Services, Health Resources and Services Administration under grant activity code T76. The views expressed in this publication are solely the opinions of the authors and do not necessarily reflect the official policies of the U.S. Department of Health and Human Services or the Health Resources and Services Administration, nor does mention of the department or agency names imply endorsement by the U.S. Government. The authors wish to acknowledge the programmatic support provided by Samantha Croffut and Dr. Cara de la Cruz. The authors also acknowledge Dr. Consuelo Beck-Sague and Dr. Bernadette West for their contributions to the Florida International University and the Rutgers University MCH Catalyst Programs, respectively.

Authors' Contributions All authors substantially contributed to the writing of the manuscript. CT Bozlak is serving as the lead/first author of the manuscript and was responsible for synthesizing all edits for the manuscript from the co-authors. All authors other than MM Tissue served as directors or co-directors of their MCH Public Health Catalyst Program and thus were responsible for reporting the data from their programs for this manuscript. MM Tissue contributed to the writing of the manuscript and served as the HRSA MCHB Program Officer for the MCH Public Health Catalyst Program during the majority of the time-frame that is the focus of this manuscript.

Funding Dr. Brown is the recipient of funding from the NIH/NCATS/ CTSA/New Jersey Alliance for Clinical and Translational Science grant number KL2TR003018. Dr. Howard's research is supported in part by the National Institute on Minority Health and Health Disparities/ NIH award number U54MD012393, Florida International University Research Center in Minority Institutions. The activities described in this article were completed by the MCH Public Health Catalyst Programs, which are programs funded by the U.S. Department of Health and Human Services, Health Resources and Services Administration under grant activity code T76. The views expressed in this publication are solely the opinions of the authors and do not necessarily reflect the official policies of the U.S. Department of Health and Human Services or the Health Resources and Services Administration, nor does mention of the department or agency names imply endorsement by the U.S. Government.

Data Availability Not applicable.

Code Availability Not applicable.

\section{Declarations}

Conflict of interest There are no conflicts of interest to report.

Ethical Approval Not applicable; An Institutional Review Board was consulted prior to initiation of this article, and it was determined that IRB approval was not needed to produce and publish the article.

Consent to Participate Not applicable.

Consent for Publication Not applicable.

Open Access This article is licensed under a Creative Commons Attribution 4.0 International License, which permits use, sharing, adaptation, distribution and reproduction in any medium or format, as long as you give appropriate credit to the original author(s) and the source, provide a link to the Creative Commons licence, and indicate if changes were made. The images or other third party material in this article are included in the article's Creative Commons licence, unless indicated otherwise in a credit line to the material. If material is not included in the article's Creative Commons licence and your intended use is not permitted by statutory regulation or exceeds the permitted use, you will need to obtain permission directly from the copyright holder. To view a copy of this licence, visit http://creativecommons.org/licenses/by/4.0/.

\section{References}

Agency for Healthcare Research and Quality. (2018). National Healthcare Quality and Disparities Report, 2018. Rockville, MD: U.S. Department of Health and Human Services.

Association of Maternal and Child Health Programs. (n.d.a.) AMCHP analysis of PH WINS 2017 findings: Maternal and Child Health Workforce Needs. Infographic. http://www.amchp.org/progr amsandtopics/WorkforceDevelopment/survey/Pages/default.aspx. Accessed October 21, 2021.

Association of Maternal and Child Health Programs. (n.d.b.) 2016 Title V Workforce Assessment - Survey results at a glance. http://www. 
amchp.org/programsandtopics/WorkforceDevelopment/survey/ Pages/default.aspx. Accessed October 21, 2021.

de Beaumont Foundation. (2017). Public Health Workforce Interests and Needs Survey: 2017 National Findings. https://www.debea umont.org/ph-wins/ Accessed October 21, 2021.

de Beaumont Foundation. (2021). Staffing up: Investing to improve public health services and protections. Infographic. https://debea umont.org/wp-content/uploads/2021/10/StaffingUpGraphicFIN AL.pdf Accessed October 21, 2021.

Dongarwar, D., Ajewole, V. B., Oduguwa, E., Ngujede, A., Harris, K., Ofili, T. U., Olaleye, O. A., \& Salihu, H. M. (2020). Social determinants of health in widening maternal and child health disparities in the era of Covid-19 pandemic. International Journal of Maternal and Child Health and AIDS, 9(3), 316-319.

Goodman, M. S., Plepys, C. M., Bather, J. R., Kelliher, R. M., \& Healton, C. G. (2020). Racial/ethnic diversity in academic public health: 20-year update. Public Health Reports, 135(1), 74-81.

Halverson, P. K. (2019). Ensuring a strong public health workforce for the 21st century: Reflections on PH WINS 2017. Journal of Public Health Management \& Practice, 25(2), S1-S3.

Handler, A., Klaus, J., Long-White, D., Roth, M., Greenleaf, R., Sappenfield, O. R., \& Cilenti, D. (2018). Innovations in maternal and child health: Pairing undergraduate and graduate maternal and child health students in summer practica in state Title $\mathrm{V}$ agencies. Maternal and Child Health Journal, 22, 154-165.

Hill, I., Burroughs, E. (2020). Maternal telehealth has expanded dramatically during the Covid-19 pandemic: Equity concerns and promising approaches. Urban Institute and Robert Wood Johnson Foundation Report. https://www.rwjf.org/en/library/research/ 2020/10/maternal-health-inequity-during-the-covid-19-pandemic. html. Accessed October 21, 2021.

Hutchins, V. (1994). Maternal and child health bureau: Roots. Pediatrics, 94(5), 695-699.
Kavanagh, L., Menser, M., Pooler, J., Mathis, S., \& Ramos, L. R. (2015). The MCH Training Program: Developing MCH leaders that are equipped for the changing health care landscape. Maternal and Child Health Journal., 19, 257-264.

U.S. Census Bureau. (2019). U.S. Census Bureau, 2014-2018 American Community Survey 5-Year Estimates. https://www.census. gov/newsroom/press-releases/2019/acs-5-year.html. Accessed October 21, 2021.

U.S. Department of Health and Human Services, Health Resources and Services Administration. (n.d.). Factsheet: Maternal and child health. Resource document. https://www.hrsa.gov/our-stories/ maternal-child/factsheet.html Accessed October 21, 2021.

U.S. Department of Health and Human Services, Health Resources and Services Administration, Maternal and Child Health Bureau. (n.d.a.). The Division of MCH Workforce Development. https:// mchb.hrsa.gov/training/. Accessed October 21, 2021.

U.S. Department of Health and Human Services, Health Resources and Services Administration, Maternal and Child Health Bureau. (n.d.b.). Title V Maternal and Child Health (MCH) Block Grant. https://mchb.hrsa.gov/maternal-child-health-initiatives/titlev-maternal-and-child-health-services-block-grant-program. Accessed October 21, 2021.

U.S. Department of Health and Human Services, Health Resources and Services Administration, Maternal and Child Health Bureau. (2014). Maternal and Child Health Public Health Catalyst Program. Funding Opportunity number: HRSA-15-133.

U.S. Department of Health and Human Services, Health Resources and Services Administration, Maternal and Child Health Bureau. (2018). Maternal and Child Health Leadership Competencies. Maternal and Child Health Leadership Competencies Version 4.0 (https://www.hrsa.gov). Accessed April 1, 2021.

Publisher's Note Springer Nature remains neutral with regard to jurisdictional claims in published maps and institutional affiliations. 